\title{
Migrações, populações negras e representações em Marabá, Sudeste do Pará (1913-1983)
}

Arilson dos Santos Gomes*

\begin{abstract}
RESUMO
O trabalho busca examinar, por meio dos impressos "O Marabá" e o "Correio do Tocantins", as representações dos grupos que migraram para a cidade de Marabá de 1913 até 1983. Período em que a narrativa do "pioneirismo" passa a sobrepor a presença de grupos fixados na região. Como destaca Roger Chartier "os dispositivos formais - textuais ou materiais - inscrevem em suas próprias estruturas as expectativas e as competências do público a que visam organizandose, portanto, a partir de uma representação da diferenciação social" (CHARTIER, 1991, p.186). Diante desta assertiva e a fim de analisar as diferenciações e os sentidos relacionados à migração marabaense analisou-se as fontes. Nos impressos foram interpretados conteúdos elaborados por seus colunistas referentes às representações identitárias dos grupos diversos que compõem o munícipio. As matérias analisadas constituem-se de homenagens aos pioneiros vindos do Sul e do Sudeste a estereótipos relacionados aos grupos indígenas, mestiços e negros.
\end{abstract}

Palavras-chave: Migração. Imprensa. Representação. Marabá. Sudeste do Pará.

\section{Migrations, black populations and representations in Marabá, Southeast of Pará (1913-1983)}

\begin{abstract}
The paper seeks to examine by means of the printed "The Marabá" and the "Correio do Tocantins" the representations of the groups that migrated to the city of Marabá from 1913 to 1983. The period in which the narrative of the "pioneerism" comes to superimpose the presence of groups established in the region. As Roger Chartier points out, "formal devices - textual or material - inscribe within their own structures the expectations and skills of the public they are aiming for, thus organizing themselves from a representation of social differentiation" (CHARTIER, 1991, p. 186). Faced with this assertion and in order to analyze the differentiations and the meanings related to the Maraba migration, the sources were analyzed. In the printed were interpreted content elaborated by its columnists referring to the representations of the diverse groups that make up the municipality. The materials analyzed constitute homages to the pioneers coming from the South and Southeast to stereotypes related to indigenous, mestizo and black groups.
\end{abstract}

Keywords: Migration. Press. Representation. Marabá. Southeast of Pará.

Artigo recebido em 26 dez. 2018.

Aprovado em 01 abr. 2019.

\footnotetext{
* Doutor em História pela Pontifícia Universidade Católica do Rio Grande do Sul (PUCRS). Professor Adjunto dos Cursos de Antropologia e de Humanidades da Universidade da Integração Internacional da Lusofonia Afro-Brasileira (UNILAB); membro permanente do corpo docente do Mestrado Interdisciplinar em Humanidades (MIH-UNILAB). Email: arilsondsg@unilab.edu.br.
} 


\section{Introdução}

Este trabalho busca examinar, por meio dos impressos "O Marabá" e "Correio do Tocantins", as representações dos grupos que migraram para a cidade de Marabá entre 1913 e 1983. Período em que a narrativa do "pioneirismo" passa a sobrepor a de grupos anteriormente fixados na região.

A pesquisa decorre de um projeto que visa a intensificar a produção de uma história da

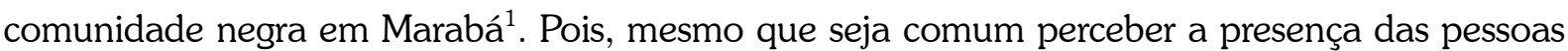
identificadas com esse grupo em seu cotidiano, os estudos sobre a sua história e a sua cultura ainda são incipientes. Estudos que somente podem ser desenvolvidos a partir das relações desse grupo com questões abrangentes.

Este trabalho desenvolve aspectos da história cultural $e$ da sua interface com as dinâmicas econômicas e sociais da região Sudeste do Pará, em específico as representações relacionadas à migração.

Como destaca Roger Chartier, "[...] os dispositivos formais - textuais ou materiais inscrevem em suas próprias estruturas as expectativas e as competências do público a que visam organizando-se, portanto, a partir de uma representação da diferenciação social" (Chartier, 1991, p. 186). Diante dessa assertiva, e a fim de analisar as diferenciações e os sentidos relacionados à migração marabaense, analisou-se os periódicos locais.

Os impressos "O Marabá" e o "Correio do Tocantins" foram problematizados a partir dos discursos formulados por seus colunistas, identificados como responsáveis pela elaboração dos códigos e dos valores identitários representados à sociedade local. Contudo, como alerta Roger Chartier, as representações são dinâmicas e de embates, já que, nas palavras do autor: "[...] as obras e os objetos produzem sua área social de recepção, muito mais do que as divisões cristalizadas ou prévias o fazem" (Chartier, 1991, p.186).

A cidade amazônica de Marabá, situada no sudeste do Pará, na foz dos Rios Tocantins e Itacaiúnas, foi formada entre o final do século XIX e início do XX. A sua trajetória é comumente associada aos fatores econômicos identificados na pecuária, no comércio e no extrativismo, bem como nos conflitos motivados pelos fluxos migratórios e disputas pela posse da terra.

A palavra "marabá", na língua tupi-guarani, pode significar: "a raça do francês", "gente que é procedente do estrangeiro", "o que é variado" e "o que varia de cores". A palavra era usada, também, para indicar as pessoas nascidas das misturas de indígenas com brancos; mestiços.

Todavia, sem romantismos, Idelma Santiago da Silva ressalta que existiram tensões 
nesses contatos. Inclusive, a pesquisadora aponta que foi na ocorrência da disputa com os indígenas pela terra e pelos recursos naturais que se assentou a narrativa dos "pioneiros" como migrantes fundadores do território. Uma refundação que se fez pela tentativa de "eliminação" dos indígenas das terras e da história do médio Tocantins. No final da década de 1970, “[...] com um novo modelo de ocupação da região os migrantes paulistas aliados às oligarquias locais passaram a representar o desenvolvimento, enquanto caboclos, indígenas e negros foram sistematicamente estigmatizados" (Silva, 2010, p.01-17).

O recorte temporal deste trabalho vai do ano de 1913, ano em que Marabá ganha sua autonomia municipal com o território desmembrado de São João do Araguaia, até 1983, período em que a cidade completou 70 anos de existência e (com a aproximação das eleições diretas) identificam-se os esforços para a elaboração de uma identidade local.

Diante disso, nos impressos foram explorados conteúdos elaborados por seus colunistas referentes às representações identitárias dos grupos diversos que compõem o munícipio, formados de grupos étnicos e sociais. As matérias analisadas constituem-se de homenagens aos pioneiros vindos do Sul e do Sudeste, a estereótipos relacionados aos grupos indígenas, mestiços e negros.

Para a pré-análise e análise qualitativa de conteúdo (Bardin, 2009), utilizou-se como corpus documental as matérias dos jornais citados, que aludiram, em sua semântica, aspectos ou expressões relacionadas aos grupos formadores da cidade.

Algumas problemáticas são pertinentes para as intenções deste artigo. Como os grupos formadores da cidade foram representados na imprensa local? Existiram diferenciações? E quanto às populações negras? Com destaques para essas problematizações, a narrativa pretende caracterizar Marabá, sua origem, a migração, o território, os conflitos e as transformações econômicas e sociais ocorridas no contexto da ditadura civil-militar. Também busca investigar como os colunistas e redatores inscreviam determinados grupos, em específico as populações negras (pretas e pardas) nos conteúdos dos jornais, sobretudo, em relação à migração.

\section{Marabá: origem, migração, território, conflitos e transformações econômicas e sociais}

Nas terras de Marabá, existiram milhares de indígenas, entre potys, tucanos, karajás, javaé, xambioás, assurini, parakanã, gavião, arara, caiapó, suruí, jakundá e outros, que "[...] com as transformações desapareceram ou mudaram-se para o centro da mata" (Filho, 2000, p.11). 
A primeira migração aos limites espaciais que se tornariam Marabá foi realizada em 1892, pelo Coronel Carlos Gomes Leitão. A caravana era composta por goianos, maranhenses e cearenses, e foi motivada pela criação de gado e pelo extrativismo da castanha, paulatinamente substituída pela extração do látex. Devido a isso, os "pioneiros" da região se deslocaram do interior e se fixaram na confluência dos Tocantins e Itacaiúnas para facilitar o escoamento da produção e trocas de mercadorias. "Na época foi criado o Burgo do Itacaiúnas".

Conforme Rovaine Ribeiro, o burgo era formado em "[...] 1896 por 222 habitantes, sendo 55 famílias." Eram "Vaqueiros, agricultores, comerciantes, antigos proprietários de terras do Maranhão, de Goiás e de indígenas das matas próximas" (Ribeiro, 2010, p.16).

Se para as rotas fluviais comerciais o local era próspero, para as condições humanas era péssimo, em virtude de inundações e febres. Por isso, houve um deslocamento para um local mais favorável. Com a exploração do caucho, a foz do Itacaiúnas ganha novo interesse.

Em 7 de junho de 1898, o militar e comerciante Francisco Coelho (1846-1906), vindo de Grajaú/MA, inaugurou um barracão de comércio na localidade, à margem direita do rio Itacaiúnas, em um ângulo agudo formado pelos dois rios. "Marabá, no seu início, era assim. Muito mais que no caso de Burgo, sua função primordial era o comércio" (Velho, 2009, p.37).

Foi com o extrativismo da borracha em seu período áureo que, por sua localização estratégica, definitivamente a cidade se formou. Nesse momento, a região amazônica era responsável por $90 \%$ da produção mundial de borracha (Ribeiro, 2010).

Para Otávio Guilherme Velho, nesse contexto, os comerciantes de Marabá ganham importância local e "[...] sentindo-se abandonados pelo Governo do Pará, criam uma comissão, vão a Belém e representam Goiás no sentido de serem incorporados a esse estado" (Velho, 2009, p.38). O movimento tem sucesso. "Em 1913, Marabá ganha sua autonomia municipal, com território desmembrado de São João do Araguaia"².

Em 1914, foi realizada a primeira eleição, quando foi eleito o intendente Antônio Rocha Maia. Em 27 de março, foi instalada, por conta do "Decreto n 3.057, de 7 de fevereiro de 1914, a primeira comarca de Marabá, assumida pelo juiz de direito, Dr. José Elias Monteiro Lopes" (O Marabá, 1983, p.04). Assumia a justiça um doutor negro "[...] diante da massa popular festeira e de 47 eleitores que se dispuseram a assinar a ata do evento" (Montarroyos, 2014, sp). José Elias Monteiro Lopes, primeiro juiz de Marabá, foi irmão do primeiro deputado federal negro do Brasil, Manuel da Motta Monteiro Lopes ${ }^{3}$.

Terceiro deputado mais votado da Capital Federal, com 2.337 votos, Manuel Monteiro Lopes, em virtude do preconceito, corria o risco de não ser diplomado. O seu caso desencadeou um grande debate público, ressoando no congresso, na imprensa, nos sindicatos, nas instituições 
de ensino, nas ruas e nas esquinas ${ }^{4}$. A cor na política era a polêmica do momento na capital federal; mas, como se nota, não em Marabá. Nesse momento, a cidade estava se formando e era considerada um espaço inóspito de difícil acesso.

Segundo estudos de Ramon Cabral e Heraldo Montarroyos, entre 1900 e 1950, o caucho (látex), a castanha, o diamante e o cristal de rocha obrigaram a constante locomoção da população trabalhadora para a cidade, que:

[...] ficava em constante movimento corporal, tanto no verão como inverno. Da mesma forma, entre o tempo dos castanhais (inverno) e o tempo da garimpagem de diamantes e dos cristais de rocha (verão, nas décadas de 1940 e 50) havia também o tempo dos caçadores e dos pescadores que exigia igualmente longas caminhadas e fazia parte das duas estações. No período 1900-1950 o nomadismo foi essencial na formação da identidade do povo marabaense e no seu imaginário cultural (Montarroyos; Cabral, 2015, p.53).

Diante das descrições iniciais da origem do município, e pelo contexto pós-abolicionista $e$ republicano, destaca-se que a escravidão, ao menos formal e jurídica, não constituiu um sistema de produção característico de Marabá. Entretanto, as populações negras descendentes de escravizados permaneceram na região, visto que o comércio transatlântico de seres humanos foi ativo nas terras da antiga capitania do Grão-Pará 5 .

A extensão é uma das principais características desse território em estudo. Para compreender suas antigas dimensões, reportamos ao censo de 1940. Na ocasião, o município de Marabá tinha $89.831 \mathrm{~km}^{2}$ (era cinco vezes maior do que o tamanho atual), compreendendo os distritos de Marabá, Jacundá, Itupiranga, Santa Isabel do Araguaia e São João do Araguaia. No período, o município era oficialmente povoado por 11.709 pessoas, sendo 7.052 homens e 4.657 mulheres. Contava-se também com a presença dos estrangeiros que totalizavam 93 pessoas, sendo 68 homens e 25 mulheres (Montarroyos; Cabral, 2015, p.56).

Montarroyos, em consonância com o censo oficial, aponta que, em 1940, a população era predominantemente branca, totalizando 6.262 pessoas. Em segundo lugar, ficavam as de cor preta, em um total de 3.955 pessoas; em terceiro lugar, vinham os pardos, representados por 2.324 pessoas. Por último, os amarelos (asiáticos) eram representados por 4 pessoas (Montarroyos, 2014, sp). Ou seja, em termos absolutos os "não brancos" (pretos e pardos) formavam a maioria da população, com 6.279 indivíduos.

Cabral e Montarroyos confirmam que a maioria da população na década de 1950 era masculina e solteira. "Os homens solteiros eram 5.452 indivíduos, enquanto as mulheres solteiras, 2.808. Já os casados somavam 2.065 homens e as mulheres, 1.469 indivíduos" (Montarroyos; Cabral, 2015, p.56). 
Diante dessa demografia e da cultura extrativista, com o "[...] tempo dos castanhais (inverno) e o tempo da garimpagem de diamantes e dos cristais de rocha (verão)", a cidade de Marabá serviria como ponto de encontro para a grande população nômade, masculina e solteira de trabalhadores extrativistas da castanha, que "[...] em constante locomoção pelo sul e sudeste do Pará aproveitava o núcleo urbano como local de descanso e diversão, buscando mulheres solteiras e prostitutas entre os anos de 1900-1950" (Montarroyos; Cabral, 2015, p.56) .

Por isso, a cidade se constituiu como um território conturbado, em que dinheiro, farra, diversão e desavenças projetavam as relações sociais entre castanheiros, patrões e prostitutas, em um sistema denominado "capitalismo selvagem" (Montarroyos; Cabral, 2015, p.56). Conforme Jonas Almeida, "[...] normalmente, ao chegarem em Marabá os trabalhadores procuravam as pensões para ser vistos e posteriormente contratados no serviço de coleta. Muitas vezes o castanheiro se hospedava com a roupa do corpo" (Almeida, 2016, p.58). Na maioria das vezes, o dinheiro era adiantado e gasto em casa de diversões gerenciadas pelos próprios patrões. Para Velho, "Marabá se enche de uma população instável, flutuante e aventureira. Desde o início é marcada pelo signo da turbulência, de que não dissocia sua fama” (Velho, 2009, p.38).

Nesse contexto, na década de 1950, o negro José Curcino de Azevedo assume como vereador. Cargo que iria renunciar em 1956, “[...] alegando que suas atividades como procurador judicial da prefeitura coincidiam com o horário das Sessões da Câmara de Marabá. Naquele tempo não havia licença do cargo para assumir outro". Curcino era procurador municipal, promotor, advogado e escritor (História do Legislativo de Marabá, 2000, p.43) 7 .

Alguns anos depois, em 1964, foi instaurado, no Brasil, "[...] por meio de um Golpe civilmilitar, o regime ditatorial" (Sader, 1982, p.150) ${ }^{8}$. Esse fato político teve desdobramentos diretos na cidade de Marabá e na região, pois nesse território, vasto e conturbado, eclodiu "A guerrilha do Araguaia", movimento armado de luta contra a ditadura que teve como um de seus expoentes o líder negro Osvaldo Orlando da Costa (1938-1974), o Osvaldão.

"Alto $(1,98 \mathrm{~m})$ e forte [...] Osvaldão comandou um dos três grupos da guerrilha (Destacamento B), que juntos reunião 69 militantes do PC do B e outros vinte aderentes" (Folha de São Paulo, 2001, p. A9). A Guerrilha do Araguaia teve lugar no sudeste do Pará e no norte do então estado de Goiás (atual Tocantins), também abrangendo terras do Maranhão, na área conhecida como 'Bico do Papagaio',

Os primeiros paulistas, como eram conhecidos os integrantes da guerrilha pelas populações locais, começaram a chegar à região do Bico do Papagaio em 1966. A partir de 1970, até 1972, vários militantes do PC do B, com diferentes profissões, vieram à região. "Havia operários, camponeses, bancários, enfermeiras, engenheiros, geólogos e, principalmente, 
estudantes universitários que viam na luta armada uma forma de resistência ao regime militar vigente no Brasil” (Silva, 2008, p. 26) ${ }^{10}$.

O exército descobriu o foco no final de 1971 e efetuou três campanhas na região entre abril de 1972 e março de 1974 - quando Osvaldão foi morto com um tiro nas costas desferido por um jagunço. Segundo o historiador Jacob Gorender, seu corpo foi atado a um helicóptero e exibido nos povoados para servir de exemplo (Folha de São Paulo, 2001, p. A9).

Nesse período, "[...] o espaço passou a ser considerado pelo exército como Área de Segurança Nacional” (Almeida, 2016, p.21) ${ }^{11}$. A partir do momento em que o Exército e a Aeronáutica se estabeleceram na região (1972-1975), mudou o cotidiano das pessoas. "Embora boa parte não soubesse o que estava acontecendo, muitas preferiam usar a tática do silêncio" (Silva, 2008, p.40). Em 1974, a guerrilha comunista foi definitivamente derrotada pelos militares. Segundo estimativas, "Pelo menos 59 guerrilheiros foram mortos na região do Araguaia em uma guerra que durou três anos e mobilizou 20 mil homens do exército" (Folha de São Paulo, 2001, p. A9).

Ademais, até a chegada das estradas federais e estaduais (a partir de 1969), como a PA70 e a Transamazônica em 1971 (BR-230), todas as atividades em Marabá eram direcionadas aos rios. A Transamazônica, chamada de "rodovia da integração nacional", atravessou a cidade de Marabá e efetivou a ocupação da Amazônia. Em 1972, ocorreu a distribuição de lotes de terras às margens das novas rodovias. Outro projeto na cidade capitaneado pelos militares foi o "Projeto Ferro" para intensificar a extração do minério da Serra dos Carajás ${ }^{12}$.

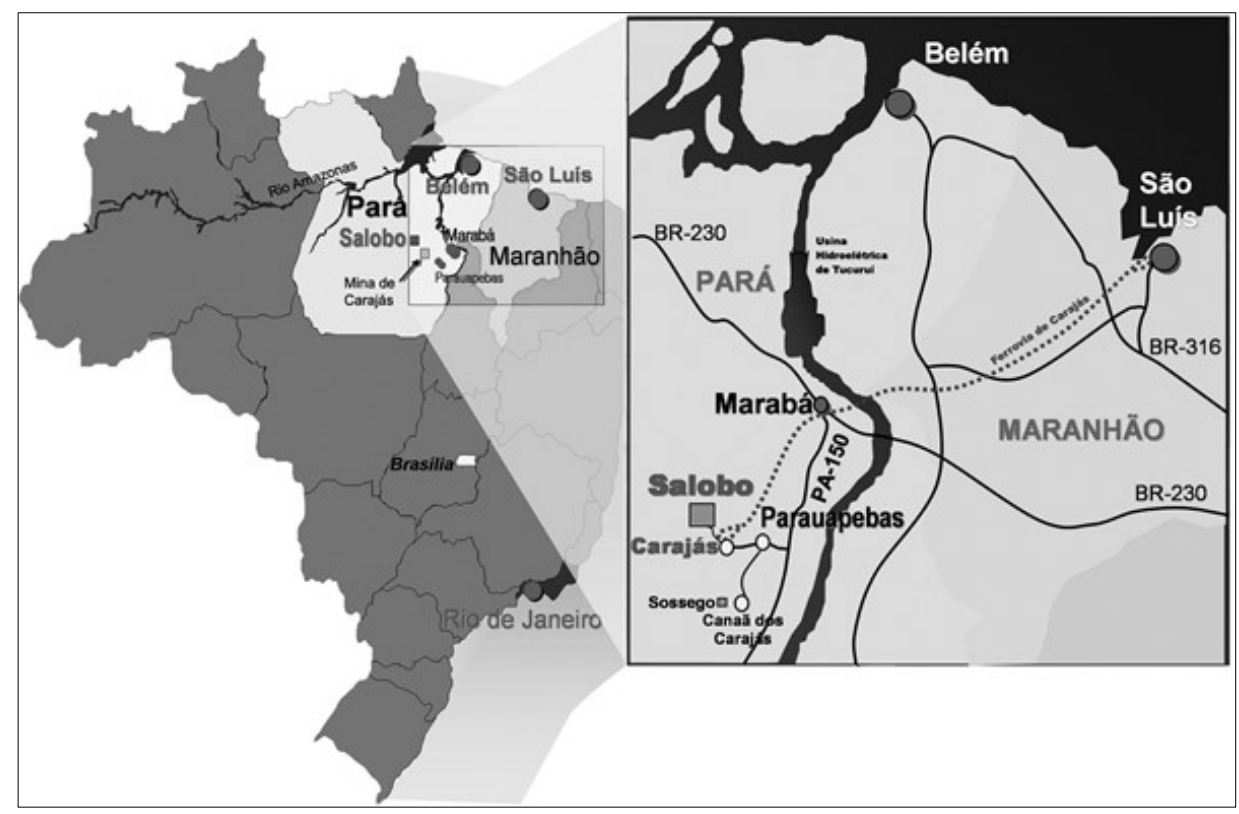


Figura 1 - Destaque para a região dos Carajás e de Marabá, área do "Projeto Ferro". ${ }^{13}$

$\mathrm{Na}$ imagem, observa-se o projeto da empresa Salobo Metais S/A. Em pontilhado, visualiza-se a estrada de ferro que transporta minérios de Carajás, passa por Marabá até São Luís/MA para exportação. Na imagem, também se observa a BR 230 (Transamazônica) e a estadual PA 150 e PA 70.

Com o novo incentivo de ocupação do território - planejado no período civil-militar e intensificado pelos recentes acontecimentos relacionados à guerrilha - tem-se na década de 1980: por um lado, a atualização da memória dos antigos "pioneiros", por outro, a estigma a determinados grupos étnicos e sociais.

Para José Jonas Almeida, as estratégias políticas do Estado beneficiam empreendimentos:

[...] as novas estratégias políticas de segurança nacional, desenvolvimento $e$ modernização justificaram as ações do Estado na Amazônia, levando o controle do espaço regional pela União e privilegiando os 'modernos' empreendimentos financiados com recursos públicos e incentivos fiscais (Almeida, 2016, p.148).

Como aduz Idelma Santiago da Silva, "[...] índios, negros (quilombolas) e caboclos têm sido considerados nos planos e nos projetos econômicos para a região como sendo portadores de uma cultura pobre, primitiva, tribal e, portanto, inferior." Em seu importante estudo, Idelma Santiago destaca que o discurso da migração começa a operar para produzir os sentidos das relações para "fora" e para "dentro" da região (Silva, 2010, p. 03).

A narrativa da colonização do Norte do Brasil, nesse período, revela a vinda de migrantes do Sul e Sudeste, com destaque para os paulistas, evidentemente não relacionados à guerrilha, mas considerados agora os novos "colonizadores". As antigas elites (oligarquias) regionais, assim como esses novos "bandeirantes", tiveram seus interesses favorecidos pelas ações do governo federal (Petit, 2003, p.183). Situação que não resolveu e, sim, agravou os conflitos pela posse da terra no município.

\section{A representação da negritude e das identidades formadoras da cidade nos impressos}

Idelma Santiago da Silva, em seu estudo, assevera que "[...] o IBGE considera sob a denominação de 'pardos' referências diversas de cruzamentos de cor ou raça. Em síntese, é o lugar estatístico da manifestação da ideologia da mestiçagem brasileira" (Idelma, 2006, p. 66), situação constatada por Kabengele Munanga (2004). Contudo, para Idelma: "[...] tem-se uma situação cultural da disseminação da maldição da cor e da discriminação racial[...]" em Marabá. 
Todas essas questões “[...] contribuem para que denominações de cor, através de processos de autoatribuição, sejam permeadas pelas ambiguidades e contradições da formação sócio-histórica da região", o que "[...] significa a invisibilidade estatística de uma parcela maior da população negra[...]" e a consequente afirmação do mito da democracia racial (Idelma, 2006) ${ }^{14}$.

Ao todo, na elaboração deste artigo, foram examinadas seis (6) notícias. Cinco (5) matérias de "O Marabá" e uma (1) do "Correio do Tocantins". As interpretações decorreram a partir do recorte e da seleção das matérias ${ }^{15}$. As análises dos jornais apontam indícios de como a imprensa transmitia aos seus leitores determinadas informações sobre as identidades formadoras de Marabá no início da década de 1980.

O jornal "O Marabá", dirigido pela família Sarmento, foi fundado no dia 13 de setembro de 1964. Portanto, em pleno período da ditadura civil-militar. Com periodicidade semanal, seu slogan enfatiza "os assuntos da região" (O Marabá, 1983, p.03) ${ }^{16}$. O outro periódico liderado por Mascarenhas Carvalho e os irmãos Costa, o "Correio do Tocantins", diferentemente do anterior, foi fundado no período em que se discutia a abertura política, em 15 de janeiro de $1983^{17}$.

Como o observado, os núcleos familiares estiveram na origem tanto do "O Marabá" como do "Correio do Tocantins". Vínculo que, igualmente, ocorreu entre os principais colunistas de ambos periódicos: Frederico Carlos Morbach e Augusto Bastos Morbach (1911-1981), pai e filho, respectivamente. Outro colunista identificado nas matérias examinadas foi Dorivan Dourado ${ }^{18}$.

A partir deste instante, serão interpretadas as matérias com destaque para as representações de grupos. As primeiras matérias analisadas foram as alusivas aos 94 anos da abolição da escravidão oficial no Brasil.

Em o "O Marabá", na edição publicada com datas de 16 a 24 de maio de 1982, Antônio Bastos Morbach homenageia a princesa Isabel, considerada como a principal figura da abolição, em virtude da assinatura da Lei Áurea ${ }^{19}$. Ademais, o autor "rememora" personagens marabaenses descendentes "da cor africana".

Para Antônio Morbach:

Ao transcurso neste, 13 de maio de 1982, noventa e quatro anos da abolição da escravatura no Brasil, ato da princesa Isabel, rememora personagens da cor africana e que foram gente notável em Marabá. Vamos começar relembrando o primeiro agente dos correios, o Josué Marinho. Preto de estatura mediana. Grande liderança exerceu outro descendente de africanos: o Messias José de Souza, um dos pecuaristas, que residia a margem esquerda do Tocantins, onde temos a cachoeira Mãe Maria. Messias recebeu dos ameríndios da tribo Gavião, tratamento de "papai grande". Índios que impediam o trabalho de coleta de castanha naquela área. Aceitavam, no entanto, os castanheiros do Messias, e todos anos vinham até uma praia pouco acima da residência do Messias, onde 
deixavam presentes e de onde levavam os presentes dos amigos. Outro líder de cor preta, o Sérvulo Ferreira de Brito, membro do Conselho Municipal (agora Câmara de Vereadores). Do gênero feminino, relembramos Auta Santos que morreu pedindo esmola nesta Marabá. Foi vítima do filho, o Leopoldo Santos, que estudando em Belém, gastava dinheiro na zona do meretrício. Dois pretos que exerceram funções elevadas no judiciário: Manuel Pedro de Oliveira, que foi Juiz de Direito da Comarca no transcurso de dez anos. E faleceu, em Belém, como desembargador do Tribunal de Justiça. Era pai de um que exerceu as funções do Prefeito Municipal de Belém [...] o dr. Ajax de Oliveira, Cursino Azevedo, alto, magro e poeta de muita inspiração [...] (Morbach, Antônio. O Marabá, 1982, p.01. Grifos nossos).

No texto citado, Antônio Bastos Morbach parece homenagear personagens "da cor africana" com quem, de certa maneira, conviveu, já que teve a intenção de "relembrar" as figuras de destaque que viveram no cotidiano da comunidade local. $\mathrm{O}$ autor denomina a identidade de seus conhecidos como "cor preta", cor oficial identificada às populações descendentes de africanos de acordo com o IBGE.

Os "pretos" Josué Marinho, funcionário dos Correios; Messias José de Souza, pecuarista que manteve relações com representantes indígenas do Grupo Gavião e Sérvulo Ferreira de Brito, membro do Conselho Municipal, foram citados pelo colunista. As aproximações de Messias - preto e pecuarista - com a comunidade indígena evidenciam as dinâmicas econômicas, culturais e sociais ocorridas entre os grupos indígenas e as populações negras existentes em Marabá.

Contudo, chamou-nos atenção o seu registro sobre a única pessoa do "gênero feminino" citada, Auta Santos, que "morreu pedindo esmola na cidade". Auta, cabe observar, foi também a única pessoa a ser destacada por algo inusitado. Diferentemente dos homens que foram delineados na escrita do autor pelas suas qualidades e conquistas.

Por fim, Antônio Morbach cita os pretos que se destacaram no poder judiciário local, como Manuel Pedro de Oliveira, Ajax Oliveira e Curcino Azevedo. Este último, descrito como "alto, magro e poeta de muita inspiração", também foi vereador, como identificado na primeira parte do texto. Outra figura negra de destaque no município, mas que não foi citada pelo colunista, foi o rábula Basílio Miguel dos Santos. Conforme Aziz Mutran Filho, o período em que esses homens atuaram, em sequência, no judiciário local ficou conhecido no meio político como a época da "justiça negra" (Filho, 2000, p.18).

Ressalta-se, novamente, que as homenagens a Isabel foram destaques nas escritas sobre a "libertação", como se fosse uma simbiose a sua figura com a comunidade afrodescendente local, o que é demonstrado na matéria a seguir. 
Com o codinome de "Vereador do Povo", o outro colunista do periódico referenciou a data da seguinte maneira: "Congratulo-me com todos os nossos irmãos de cor, que neste treze de maio, a noventa e quatro anos atrás eram libertados das correntes vergonhosas do cativeiro, $e$ rendo as minhas homenagens post- mortem a figura histórica de Izabel (sic)". Muito obrigado!" (Vereador do Povo, O Marabá, 1982, p.03) ${ }^{20}$.

Aqui, além da homenagem a Isabel, evidencia-se, na escrita, que os afrodescendentes da cidade são denominados "irmãos de cor". O que define uma linha demarcatória entre o "nós" e o "eles", situação atinente ao processo identitário historicamente construído.

Salienta-se que, nesse contexto, a cidade estava prestes a completar 70 anos de emancipação, a serem comemorados em 1983. Nesse sentido, "O Marabá" iniciou uma campanha visando preservar a memória dos primeiros habitantes do município, considerado como "os pioneiros". Inclusive, o periódico passa a sensibilizar a opinião e o poder público para a construção de um monumento ${ }^{21}$.

Nesse instante, os jornais analisados passam a servir de maneira prática aos interesses das representações dos grupos hegemônicos vinculados aos vencedores. Migrantes que seriam os portadores do progresso $e$ do desenvolvimento em detrimento dos povos negros $e$ indígenas, que eram grupos considerados portadores do atraso e do retrocesso.

Para o jornal: "Marabá é a São Paulo, do Norte do País, uma vez que abriga, uma mescla de cores, tipos e sotaques diferentes inclusive estrangeiros provenientes de diversos países" (O Marabá, 1982, p.02). Assim, o jornal elogia a "mistura" identificada na identidade dos indivíduos que compõem a cidade. Porém, com relação aos "pioneiros", o periódico rememora que eles foram:

[...] heróis que deram um pulo para o desconhecido quando entraram num batelão pelos grandes rios infestados de feras, índios, febres e perigos mais [...] dai o valor que as autoridades terão que dar aos heróis desconhecidos, heróis anônimos. Precisamos erigir um monumento a esses injustiçados (O Marabá, 1982, p.02. Grifos nossos)

Tem-se, nessa passagem, uma situação problemática, visto que os "índios" são tratados, literalmente, como os "outros", e são comparados a "feras" e aos "perigos" enfrentados e superados pelos "pioneiros". Estes, sim, "injustiçados" e merecedores de um monumento.

A maioria dos migrantes das últimas três décadas do século $\mathrm{XX}$, que se deslocaram para o sudeste do Pará (médio Tocantins), é constituída de sujeitos das classes subalternas. Como salienta Idelma Silva: 
No sudeste do Pará, dos imbricamentos dos discursos dos 'pioneiros' e dos 'bandeirantes' a definição dos 'outros' das relações socioculturais se torna objeto das lutas de representação. De um lado, a migração ganha sentidos positivos quando se trata de definir a região em alteridade com o norte do Estado ou à Amazônia [...]. Por outro lado, a migração, internamente, é construída como problema quando integrada por pobres, sobretudo maranhenses e de outros Estados nordestinos. Desde então, os maranhenses passaram a ser indesejados [...] 'eliminado' o índio - tornava 'imperiosa' nova classificação sociocultural que designasse aquele a ser "etnicizado" e fornecesse os "braços" para o trabalho mais penoso e degradante de exploração econômica - as atividades que "possuíam" o território (Silva, 2010, p.11).

Indígenas e negros passam a ser diferenciados. Idelma Santiago da Silva interpretou variadas fontes em sua pesquisa, especialmente material de jornal impresso, rimas de histórias e anedotas a respeito desses "outros". Nas rimas de histórias, sobressaem representações correntemente reiteradas sobre os maranhenses migrantes e sobre o Maranhão: (i) o maranhense está na história, mas em uma condição de existência humana rebaixada/desqualificada e, pior, (ii) é uma questão ontológica (imanente de seu ser), um estigma. Em outros textos, “[...] sobressaem representações do maranhense como aquele que se multiplica com intensidade primitiva e espalha-se como 'praga' para fronteiras próximas e distantes" (Silva, 2010, p.14).

Percebe-se, no cotidiano da cidade de Marabá, que perduram as representações negativas e os estereótipos relacionados ao fenótipo do sujeito maranhense como sinônimo de ex-escravizado. Nesse grupo, é reforçado, fixado e reproduzido o discurso do passado colonial. Situação diferente é dispensada nas linhas dos impressos quando se trata de referenciar os representantes dos grupos considerados "pioneiros".

Em se tratando de "pioneiro", o nome de Francisco Coelho da Silva também foi destacado, pois, como já narrado, esse era considerado o principal fundador do espaço que originou a cidade, identificada no barracão denominado "Marabá"22.

Já em 1983, por ocasião dos 70 anos da cidade, foi publicada uma matéria reveladora quanto às qualidades impingidas ao empreendedor "pioneiro". Independentemente da forma de seu empreendimento, ele é considerado "inteligente" e "estratégico" pelos redatores do Jornal "O Marabá". Segundo a matéria:

A fama de produção caucheira se espalhava cada dia mais, e outro não menos aventureiro, Francisco Coelho da Silva, pensou e pensou bem, montou uma casa comercial e ganhou muito dinheiro de um modo bem inteligente. Ao descer rio abaixo Chico Coelho, escolheu estrategicamente a confluência dos dois grandes rios Tocantins e Itacaiúnas e ali construiu o famoso 'Barracão', Marabá (O Marabá, 1983, p.06).

O plano de Francisco Coelho, além de ter erigido um barracão em local apropriado, 
consistia em manter no seu estabelecimento comercial uma casa de prostituição. "Caboclas de pele morena, dispostas a orgias", completaram seu empreendimento. Nas linhas do periódico, o primeiro cuidado de Chico Coelho:

[...] foi trazer algumas mulheres, caboclas de pele morena, fortes e dispostas a muitas orgias e festas. Logicamente, estas festas atrairia a atenção de todos os extratores de 'caucho' que forçosamente teriam de passar ali. Chegados ao barracão, aportavam e metiam a cara na farra com as belas caboclas do Chico Coelho. Ele sabia como ninguém aproveitar as oportunidades [...] (O Marabá, 1983, p.06. Grifos nossos).

A "inteligência" de Chico Coelho retratada pelo jornal era diretamente associada à maneira com que ele utilizava as "belas caboclas de pele morena" para fisgar os trabalhadores do caucho, que deixavam o seu dinheiro no barracão.

Outrossim, destaca-se que o impresso pouco se importa com a moralidade em torno das ações do "pioneiro", assim como não se preocupa sobre em que condição essas mulheres foram arregimentadas. Entretanto, a cor da pele dessas mulheres e as suas "qualidades" não passam despercebidas nas escritas do impresso, sendo destacadas como "caboclas fortes" agregadas a "orgia", "festas" e "farra". Ademais, as "caboclas" eram "propriedades" do "visionário" Chico Coelho.

Segundo Aziz Mutran Filho, memorialista da região, o barracão era afastado de onde residiam famílias. "No barracão Coelho vendia bebidas alcoólicas e a noite, promovia festas dançantes [...]. As damas eram na maioria pretas do antigo quilombo, que então já se dissolvera [...]" (Filho, 2000, p.13) ${ }^{23}$. Todavia, na visão do memorialista, as mulheres de Chico Coelho eram as pretas do quilombo. Já para as linhas de "O Marabá", elas eram caboclas e morenas. Todavia, as suas imagens foram representadas ao meretrício em ambas as fontes. Já Chico Coelho foi enaltecido.

A última matéria examinada em "O Marabá", sobre as representações identitárias da região, evidencia-se como incompleta a ideia de brasilidade identificada na narrativa de Dorivan Dourado. O colunista divulgou a Festa Junina como um evento: [...] integrante do calendário folclórico do Brasil [...]. Estas festas fazem parte da herança de portugueses e africanos, influência cultural que baseamos no nosso dia a dia; que desde o Brasil Colônia, cultuamos com todo o carinho e brasilidade [...]" (Dourado, Dorivan, O Marabá, 1983, p.04).

Define-se a citação de Dorivan Dourado como uma brasilidade enviesada devido ao fato de ele ter mencionado a festa, a herança cultural brasileira, somente a partir de "portugueses e africanos" e, notadamente, de ter silenciado a contribuição dos "índios". Seria proposital o silenciamento dessa contribuição na escrita do colunista? O "carinho" citado por ele, entre 
portugueses e africanos, em torno da brasilidade, estaria relacionado à ideologia freyreana de "democracia racial"? Provavelmente ${ }^{24}$. Porém, o silenciamento em torno das contribuições indígenas evidencia o grau de marginalização a que esses grupos foram submetidos na cidade de Marabá, como interpretou Idelma Silva. Mesmo sendo uma cidade decantada pela mestiçagem e pela ideologia da harmonia das raças, desde a sua formação - ao menos na matéria analisada manteve-se a invisibilidade dos grupos indígenas, o que caracteriza uma política do silenciamento ${ }^{25}$.

No outro jornal analisado, o "Correio do Tocantins", edição de julho a agosto de 1983, na seção "Opinião", localizou-se uma interessante referência aos indivíduos negros de Marabá. Frederico Carlos Morbach, pai de Antônio Bastos Morbach do jornal "O Marabaense", foi o autor do texto que, entre outras situações, defendia o reconhecimento de indivíduos negros como representantes legítimos de Marabá.

Em sua escrita, ao invés de prevalecer a figura de Isabel para homenagear a comunidade negra (preta), como o escrito por colunistas anteriores, ou da figura de um "pioneiro" para identificar as raízes formadoras da cidade, tem-se como destaque o "Nego Capistrano" e a sua relação com a figura de "Zumbi do Quilombo dos Palmares".

Ademais, em sua visão, o "Nego Capistrano" era um filho da mestiçagem, porém, não um sujeito vinculado à ideologia do branqueamento formulada no século XIX e ainda tão em voga na região ${ }^{26}$. Ao escrever sobre a referência simbólica de Zumbi, Frederico Morbach colocase próximo à ideologia elaborada pelos intelectuais dos movimentos negros que elaboraram uma identidade negra política "[...] por meio da solidariedade entre pretos, caboclos e pardos" (Munanga, 2004, p.118).

Nas palavras de Frederico Carlos Morbach: “[...] o Nego Capistrano é mistura de anhangá com saci-pererê". Frederico Morbach narra a estória do "Nego Capistrano" como uma ficção, entrelaçada a opiniões pessoais e críticas a partir de um cotidiano em que é possível notar as tensões existentes em torno das riquezas do território e da má distribuição de renda. Mas o "Nego Capistrano", nas palavras do autor, não é um indivíduo qualquer, já que é protegido pela natureza e pelas figuras míticas das africanidades e afro-brasilidade.

Por fim, Frederico Morbach identificou Capistrano (em alusão, talvez, ao historiador João Capistrano de Abreu) com os referenciais simbólicos que permitem uma relação direta com a afirmação da identidade negra contemporânea construída pelo movimento negro. Pois, além de enfatizar a identidade de Capistrano, e de reivindicar o seu túmulo "incerto" como "um monumento histórico desta terra", denominou-o "Zumbi de Marabá" - esquecido representante dos reais bravos pioneiros. 
Segundo Frederico Carlos Morbach, "Capistrano, negro e velho" deve ter sua vida estudada, como:

[...] um exemplo de estoicismo e desprendimento, e a sua sepultura, incerta, deveria ser um monumento histórico desta terra, liderada por muitos talvez não permitissem que a história de suas vidas fosse registrada. José (sic) Capistrano de Abreu, esse Zumbi de Marabá - explorador notável - lamentavelmente passara ao rol dos esquecidos [...] esses bravos pioneiros [...] (Morbach, Frederico, Correio do Tocantins, 1983, p.04).

\section{Conclusão}

Este artigo examinou a origem migrante das populações na região Sudeste do Pará, e como os grupos étnicos e sociais foram representados nos impressos. Nesse sentido, algumas problemáticas foram pertinentes para as intenções do trabalho. Dentre elas, entender como os grupos negros foram concebidos nos jornais "Correio do Tocantins" e "O Marabá" e, ao mesmo tempo, como foram tratados os grupos formadores do município por esses jornais.

Sobre os referenciais das populações negras, teve-se a figura de Zumbi dos Palmares relacionada ao personagem do "Nego Capistrano" nas escritas de Frederico Carlos Morbach do "Correio do Tocantins", além da homenagem do colunista Antônio Bastos Morbach, do Jornal "O Marabá", às personalidades "da cor africana". São registros que auxiliam, de uma maneira ou de outra, os estudos e a afirmação positiva dos negros e das negras locais (pretos e pardos identificados com a construção política da negritude), ainda que os seus colunistas não fossem representantes orgânicos dos movimentos negros contemporâneos nesse período representado, a nível nacional, pelo Movimento Negro Unificado.

Destaca-se, nas escritas de Frederico Carlos Morbach, que o Nego Capistrano, provavelmente, seja uma alusão ao historiador João Capistrano de Abreu. Não por acaso, um dos pioneiros da historiografia brasileira no que tange à problematização das fontes pelo historiador. $\mathrm{O}$ que remete à influência da história crítica nos pensamentos e na escrita literária elaborada pelo autor ante uma história tradicional, dos vencedores e dos pioneiros convencionais aludidos nos jornais.

Quanto às referencias oficiais, essas se destacaram nas homenagens à princesa Isabel $e$ na ideia de brasilidade construída por Dorivan Dourado, colunista de "O Marabá". Contudo, Dorivan Dourado, mesmo divulgando a harmonia racial, destacou somente os africanos e os portugueses, silenciando sobre as contribuições indígenas. Situação que evidencia o grau de marginalização a que os grupos indígenas foram submetidos nas representações dos formadores da cidade. 
Caboclas, morenas e mestiças foram citadas na matéria escrita no "O Marabá" por ocasião dos 70 anos da cidade, em 1983. Nessa circunstância, a coluna destacou as orgias organizadas pelo comerciante Francisco Coelho da Silva, considerado um dos principais "pioneiros" da fundação da cidade. Tais informações, independentemente da consciência dos colunistas, difundiram preconceitos e reforçaram estereótipos contra os grupos mestiços. Esses grupos - considerados degenerados por intelectuais racistas em meados do século XIX - por meio das ideias de Oliveira Viana e, posteriormente, de Gilberto Freyre, passam a ter destaque na formação da nacionalidade brasileira. Contudo, ao menos na matéria do jornal, ainda eram tratados com indiferença.

Aliás, os grupos indígenas são constantemente obliterados nos periódicos aprofundados pela elaboração textual de uma memória moderna advinda com a reprodução de elementos vinculados à inteligência, à coragem $e$ ao desprendimento dos primeiros pioneiros que desbravaram as terras marabaenses e que passam a ser atualizados na década de 1980. São excluídos pelos redatores e colunistas adeptos a um progresso econômico advindo de uma migração aportada a latifundiários, empresários e industriais incentivados pelo Estado Brasileiro.

Por fim, cabe destacar o protagonismo identificado nas populações negras e em seus representantes para além das matérias jornalísticas interpretadas. Homens e mulheres que foram fundamentais na origem, no desenvolvimento e nos acontecimentos relevantes da cidade localizada no sudeste do Pará. Elias Monteiro Lópes, Curcino de Azevedo, Osvaldão e Auta Santos foram representantes da comunidade negra, migrantes ou nascidos na cidade, que efetivamente contribuíram para a história de Marabá, constituindo-se em importantes referenciais para a produção de novas pesquisas.

\section{Referências}

ALMEIDA, José Jonas. A Castanha do Pará na Amazônia. Jundiaí: Paco Editorial, 2016.

BARDIN, Laurence. Análise de Conteúdo. Lisboa, Portugal: Edições 70, LDA, 2009.

CAMPOS, Deivison Moacir Cezar. O Grupo Palmares (1971-1978): um movimento negro de subversão e resistência pela construção de um novo espaço social e simbólico Dissertação (Mestrado em História). Porto Alegre: Pontifícia Universidade Católica do Rio Grande do Sul - PUCRS, 2006.

CHARTIER, Roger. O mundo como representação. Revista Estudos Avançados 11, USP, São Paulo, vol. 5 n.11, Jan./Apr. 1991, p. 173-191. 
CORREIO DO TOCANTINS, edição de julho a agosto de 1983.

DOURADO, Dorivan, O Marabá, 1983, p. 04.

FILHO, Aziz Mutran. Marabá: de Carlos Gomes Leitão a Geraldo Mendes de Castro Veloso. Marabá: Prefeitura, 2000.

FOLHA DE SÃO PAULO, 2001, p. A9.

FREYRE, Gilberto. Casa Grande E Senzala. Rio de Janeiro: Livraria José Olímpio Editora S.A, 1981.

GOMES, Arilson dos Santos. O Nego Capistrano em Marabá/PA. In: LIMA, Ivan Costa et al. NUUmbuntu em Revista. Acarape: Editora Imprece, 2019, p. 105-125.

GOMES, Flávio dos Santos; DOMINGUES, Petrônio. Raça, Pós-Emancipação, Cidadania e modernidade no Brasil. In: Da nitidez e invisibilidade - Legados do pós-emancipação no Brasil. Belo Horizonte: Fino Traço, 2013, p. 305-325.

HISTÓRIA DO LEGISLATIVO. Marabá: Câmara de Vereadores, 2000.

MONTARROYOS, Heraldo Elias. "O primeiro grito federalista da Amazônia Republicana": A Origem do Município de Marabá. Revista História e História. Disponível em $<$ http://historiaehistoria.com.br/materia.cfm?tb=artigos\&id=286>. Acesso em 17 de setembro de 2014,sp.

MONTARROYOS, Heraldo Elias; Ramos, Cabral. "A ecologia desumana dos castanhais": a experiência do extrativismo na cidade de marabá (Estado do Pará, Amazônia, Brasil) entre 1900-1950. Revista Ouricuri, Paulo Afonso, Bahia, v.5, n.2, p. 53-80. jul/ago, 2015, p. 53.

MORBACH, Antônio. O Marabá, 16 a 24 de maio de 1982, p.01.

MORBACH, Frederico, Correio do Tocantins, edição de julho a agosto de 1983, p.04.

MUNANGA, Kabengele. Rediscutindo a mestiçagem no Brasil - identidade nacional versus identidade negra. Belo Horizonte: Autêntica, 2004.

NEVES, Francisco. O discurso politico partidário Sul-Rio-Grandense sob o prisma da imprensa Rio-grandina (18681895). Rio Grande: Editora da FURG, 2002.

O MARABÁ, 5 a 12 de abril de 1983, p. 04. 
ORLANDI, Eni. Orlandi. As formas do silêncio - nos movimentos dos sentidos. Campinas: Editora Unicamp, 1995.

PEIXOTO, Rodrigo Corrêa Diniz. Memória social da Guerrilha do Araguaia e da guerra que veio depois, Boletim Museu Paraense Emílio Goeldi. Cienc. Hum, Belém, v. 6, n. 3, set-dez., p. 480, 2011, p.480. Disponível em: <www.scielo.br/pdf/bgoeldi/v6n3/02>. Acesso 7 nov. 2016.

PETIT, Pere. Chão de promessas: elites politicas e transformações econômicas no Estado do Pará pós-1964, Belém: Paka-Tatu, 2003.

REIS, João José. Capistrano de Abreu (1907), O surgimento de um povo: o povo brasileiro, Revista de História da USF, São Paulo, Vol.1, n.138, 1998, p.63-82. Disponível em $<$ http://www.revistas.usp.br/revhistoria/article/view/18843>. Acesso em 07 de fevereiro de 2017.

RIBEIRO, Rovaine. As cidades médias e a reestruturação da rede urbana amazônica: a experiência de Marabá no sudeste do Pará. Dissertação (Mestrado em Geografia). São Paulo: Universidade de São Paulo, 2010.

SADER, Éder. Um rumor de botas: ensaios sobre a militarização do Estado na América Latina. Coleção Teoria e História. São Paulo: Pólis, 1982.

SILVA, Idelma Santiago da. A migração como mito fundador e outras metáforas: narrativas da colonização no sudeste do Pará. Escritas: Revista do Colegiado de História Campus Araguaína, vol. 2, 2010, p. 01-17.

SILVA, Idelma Santiago da. Migração e cultura no Sudeste do Pará: Marabă (1968-1988). (Dissertação (Mestrado em História). Goiânia: Universidade Federal de Goiás, 2006.

SILVA, Wellington Sampaio da. A guerra silenciada: Memória histórica dos moradores do Bico do Papagaio sobre a Guerrilha do Araguaia. Dissertação (Mestrado em História). João Pessoa: Universidade Federal da Paraíba, 2008.

VELHO, Otávio Guilherme. Marabá da castanha e do diamante. Frente de expansão e estrutura agrária: estudo do processo de penetração numa área da Transamazônica. Rio de Janeiro: Centro Edelstein de Pesquisas Sociais, 2009.

VEREADOR do Povo, O Marabá, 1982, p. 03.

VIANA, Francisco José de Oliveira. O tipo brasileiro. Seus elementos formadores. In Dicionário histórico, geográfico e etnológico do Brasil. Rio de Janeiro: Imprensa Nacional, 1922. 
${ }^{1} \mathrm{O}$ projeto vinculado ao Instituto de Ciências Humanas e a Faculdade de História da Universidade Federal do Sul e Sudeste do Pará (ICH-Unifesspa) - denominado Africanidades, Identidades Negras e Ideologias contou com a atuação da bolsista Lourrana Santos. O trabalho foi realizado com apoio do Programa Institucional de Bolsa de Iniciação Científica CNPq (2016-2017).

${ }^{2}$ Ainda conforme o decreto $n^{\circ} 1.278$, assinado pelo presidente do Pará, Enéas Martins "foi empossada a Comissão administrativa Municipal presidida pelo coronel Melquíades Peres Fonteneille, tendo como membros os coronéis: Antônio Rocha Maia, Afro Sampaio e Quirino Francisco Castro" (O Marabá, 5 a 12 de abril de 1983, p.04).

${ }^{3}$ Elias e Manuel Monteiro Lopes nasceram na cidade de Recife, em Pernambuco. Elias havia se radicado em Belém do Pará e intermediou, no ano de 1890 a vinda de Manuel Monteiro Lopes para o Norte do Brasil. Manuel foi nomeado promotor público de Manaus e elevado às funções de juiz de direito na mesma cidade. Por volta de 1894 , transferiu-se para a Capital Federal, Rio de Janeiro, a fim de se dedicar à advocacia. Depois de renomado advogado, entra para a vida política. Mas, para muitos membros das elites intelectuais e políticas, a presença de africanos e de seus descendentes ocupando espaços importantes significava um obstáculo para a formação do povo e a prosperidade da nação (Gomes; Domingues, 2013, p.305-325).

4 "Após longa campanha viajando pelo Brasil, com o apoio de sindicatos e organizações negras, a Comissão Verificadora acatou o resultado das eleições. No dia 01 de maio de 1909, Monteiro Lopes foi finalmente diplomado. Falecendo no ano seguinte, no dia 13 de dezembro de 1910" (Gomes; Domingues, 2013, p.140). Portanto, Manuel não presenciou a vitória o pioneirismo jurídico do irmão Elias em Marabá. Já Elias, de alguma maneira, acompanhou a epopeia do irmão.

5 Destaca-se que no Estado do Pará, região conhecida como Baixo Amazonas, encontram-se cerca de 60 comunidades remanescentes de quilombos localizadas nos municípios de Oriximiná, Óbidos, Santarém, Alenquer e Monte Alegre (CPISP, 2014). Entre 1995 e 2005, outras 28 comunidades desta localidade tiveram suas terras tituladas, abarcando aproximadamente 1.161 famílias. A área titulada no Baixo Amazonas soma 386.488,05 hectares, o que representa $43 \%$ da dimensão total de terras de quilombo tituladas no Brasil. Comissão pró-índio de São Paulo, CPISP. <http://www.cpisp.org.br>. acesso em 27 de agosto de 2016.

${ }^{6}$ Para José Jonas Almeida, que pesquisou o extrativismo da castanha no Sudeste do Pará, desde o século XVIII e XIX, essa mão de obra no: "extrativismo exige uma população de indivíduos que seja dispersa, excessivamente móvel e que não permita uma forma comum de organização. Portanto, não se verifica a submissão completa da força de trabalho, algo característico do estágio do capitalismo industrial. Os coletores preservavam certo controle sobre sua atividade e mobilidade" (Almeida, 2016, p.58).

${ }^{7}$ José Curcino teve sua memória homenageada em rua e escola de Marabá, ambas localizadas no bairro Laranjeiras, Folha 10, Quadra 14.

${ }^{8}$ Muitos foram os agentes políticos e sociais envolvidos no golpe desencadeado em $1^{\circ}$ de abril de 1964 . Contando com segurança dos militares, políticos oposicionistas, setores da grande imprensa, da Igreja e um amplo movimento civil da classe média organizada - representada, segundo Éder Sader, pelas "ideologias burguesas" - o quadro político se alterou. Os militares se propunham a "acabar com a corrupção e a subversão". Prisões e suspensões dos direitos individuais e políticos foram justificadas a fim de organizar a política nacional, para uma "rápida" volta ao regime constitucional. Para Sader, esse período serviu para a consolidação do poder da burguesia, sendo identificado nas Forças Armadas o seu "partido único" contra as forças sociais que ameaçavam a expansão econômica do capitalismo e a ascensão do comunismo (Sader, 1982, p.150-153).

9 "A guerrilha ocorreu em meados da década de 1960, quando os primeiros militantes do Partido Comunista do Brasil (PC do B) chegaram à região (o lendário Osvaldão, em 1966) até 1974, quando os últimos guerrilheiros foram caçados e abatidos por militares, especialmente treinados para combater a guerrilha" (Peixoto, 2011, p.480). Osvaldo Orlando da Costa foi campeão de boxe pelo Club de Regatas Vasco da Gama, do Rio de Janeiro, e estudou na Faculdade de Engenharia Mecânica, da Universidade de Praga, na Checoslováquia. País que teria se especializado em estratégias de luta armada.

${ }^{10}$ Para Wellington Silva, os guerrilheiros comunistas estavam seguindo as premissas do maoísmo. A estratégia dos membros do partido era a conquista da população ("massas") por meio da amizade. Após essa fase (em um segundo momento) seria feito o trabalho de conscientização política visando a conquistar os moradores para fazer parte do movimento. Nesse sentido, a guerra popular prolongada ou a guerra de guerrilhas aconteceria em um terceiro momento, quando a população ou parte dela estivesse conscientizada do seu papel. Porém, essa fase não chegou a acontecer. Os militares, ao chegarem e permanecerem na região, silenciaram o projeto do movimento e a experiência vivenciada entre guerrilheiros e moradores.

${ }^{11}$ De 1970 até 1985, Marabá passou a ter prefeitos nomeados com a aprovação do Conselho de Segurança Nacional.

${ }^{12}$ Marabá, regionalmente, compreende a região da Serra dos Carajás; com solo rico em minérios como o ferro e ouro. A empresa de metais Salobo S/A, atualmente projeto da empresa mineradora Vale, bem como o histórico garimpo de Serra Pelada, constituem as riquezas minerais deste território (Almeida, 2016). Em que pese os entraves sociais, estruturais e a má distribuição de renda percebida na cidade.

${ }^{13}$ Disponível em: http://periodicos.ufpb.br/index.php/ra/article/viewFile/2843/2448/4370. Acesso em junho de 2016.

${ }^{14}$ No censo do IBGE de 1996, somente no sudeste paraense viviam 889.404 pessoas, desta, aproximadamente três quartos da população ou 638.673 declarou-se de cor parda (71,80\%). Em Marabá, na época viviam na cidade 
123.667 pessoas, destas, mais de três quartos ou 94.744 declarou-se na mesma condição (76,61\%). Os que se declararam de cor preta formam um pequeno percentual de 4,05\% para o sudeste e 2,54\% para Marabá.

${ }^{15}$ Os impressos coletados compõem a coleção digital disponível na Fundação Casa de Cultura de Marabá - FCCM. A instituição municipal acondiciona acervos documentais e materiais arqueológicos característicos da região bem como desenvolve projetos educativos e sociais.

${ }^{16} \mathrm{O}$ seu expediente era formado pelo diretor de honra, Elson Cosme Sarmento; pelo diretor geral, Antônio Sarmento Júnior; pela Gerente Creusa Sarmento e pelo diretor social; Dorivan Dourado. Além destes, compunham a equipe "o redator, José da Silva Brandão e os colaboradores Nizan Sarmento, Cândido Costa e Luiz Tolentino" (O Marabá, 1983, p.03). Como já observado, a família Sarmento era a principal responsável pela condução do jornal, sendo localizados quatro representantes do núcleo no comando do impresso.

${ }^{17}$ Liderado pelo jornalista Mascarenhas Carvalho da Luz e mais tarde pelos irmãos Pedro Costa Júnior e Pedro Robson Holanda da Costa, o impresso era quinzenal, depois passou a circular semanalmente, sempre às sextas-feiras (Site do Correio do Tocantins, 2016). A partir de meados de 2016 o jornal passou a ser denominado de Correio de Carajás e em versão on-line de Portal dos Carajás. Disponível em <https://correiodecarajas.com.br/>. Acesso em 17 de setembro de 2017.

${ }^{18}$ Desses colunistas, o mais destacado foi Augusto Bastos Morbach (1911-1981), que manteve intensa vida intelectual em Marabá e na capital do Estado, Belém, participando da organização de revistas e de jornais. Foi Secretário da Prefeitura de Marabá em 1954 e participou do jornal "O Democrata", de Marabá, de propriedade de Aziz Mutran Neto. Destaca-se que a família Mutran é uma das famílias mais tradicionais de Marabá. Atualmente, existe na cidade uma escola municipal em homenagem a Morbach. A Escola Estadual de Ensino Fundamental Augusto Bastos Morbach.

${ }^{19}$ Nessa época, o estado passou a legitimar simbolicamente o dia 13 de maio de 1888 como o dia oficial da abolição, ou seja: para os intelectuais negros do Grupo Palmares (1978), liderados por Oliveira Silveira (1941-2009), ter (re) significado a data alusiva à memória da luta negra para a morte de Zumbi dos Palmares (1655-1695), em contraponto à data anterior, identifica a importância simbólica dessa efeméride oficial, já que, sendo contra ou a favor, ela tornou-se o parâmetro do debate sobre qual data representava melhor o protagonismo negro na resistência à escravidão e o reconhecimento político-social da liberdade (Campos, 2006). Na atualidade, identificada no dia 20 de novembro. Data da Consciência Negra, conforme a Lei 12.519, sancionada em Marabá no ano de 2011.

${ }^{20}$ VEREADOR do Povo, O Marabá, 1982, p.03.

${ }^{21}$ Entende-se que, nesse contexto, abre-se uma disputa pela representação coletiva dos marabaenses. Como aponta Roger Chartier, "[...] a representação coletiva autoriza a articular três modalidades de relação com o mundo social"; a primeira, "[...] o trabalho de classificação e de recorte que produz configurações intelectuais múltiplas pelas quais a realidade é contraditoriamente construída pelos diferentes grupos que compõem uma sociedade"; a segunda, "[...] as práticas que visam a fazer reconhecer uma identidade social, a exibir uma maneira própria de ser no mundo, a significar simbolicamente um estatuto e uma posição"; e, em terceiro, "[...] as formas institucionalizadas e objetivadas em virtude das quais 'representantes' (instâncias coletivas ou indivíduos singulares) marcam de modo visível $e$ perpétuo a existência do grupo, da comunidade ou da classe" (Chartier, 1991, p.183).

22 A categoria "pioneiro", empregada em diferentes "acontecimentos discursivos" - memorialísticos e políticopanfletários - refere-se aos (auto)denominados "desbravadores" da primeira metade do século XX. Faz parte de uma memória que tem reificado a história vivida, especialmente na reiteração dos personagens-heróis da conquista, sublinhando o papel dos "coronéis" - os "patrões sertanejos" do Maranhão e antigo norte de Goiás (Silva, 2010, p.04).

${ }^{23}$ As informações sobre os Quilombos dos Quindangues merecem aprofundamentos, já que foram extraídas de uma única fonte. Um livro escrito por Aziz Mutran (2000), que em sua primeira parte foi inspirado por relatos de sua memória. Os Mutran, família de origem libanesa, constituíram-se como uma das famílias mais influentes da história da cidade. Ainda se faz necessária a localização de documentos para sustentar de fato a existência dos Quindangues. Contudo, essa informação deve ser considerada como um indício a ser investigado.

24 O livro Casa Grande e Senzala, lançado em 1933, de autoria de Gilberto Freyre, propiciou aos intelectuais brasileiros no início da década de 1930 uma ideia de que "o português cosmopolita plástico" teria se amalgamado aos índios e aos negros, sendo esse o eixo formador de nossa brasilidade (Freyre, 1981, p.04). Nesse sentido, Dorivan silencia a contribuição indígena a amálgama referenciada.

${ }^{25}$ Segundo Eni Orlandi, a política do silenciamento consiste em invisibilizar propositadamente determinados grupos nos discursos hegemônicos, de modo a fragilizá-los (Orlandi, 1995).

${ }^{26}$ Para alguns intelectuais e políticos brasileiros, a mestiçagem torna-se uma solução para o branqueamento da nação. Oliveira Viana (1883-1957), inclusive, disse que: "quanto maior for o sangue ariano nos mestiços, mais rápido estes tenderão a revestir-se dos atributos somáticos do homem branco" (Viana, 1922, p.284). Por outro lado, Frederico Morbach pode ter sido influenciado pelas pesquisas de João Capistrano de Abreu ao projetar a saga do Nego Capistrano no Jornal Correio do Tocantins, pois o historiador Capistrano deu ênfase, de maneira positiva, ao povo mestiço na constituição do território brasileiro (Reis, 1998). 